\title{
Neurofibromatosis and Pregnancy
}

\author{
Reyhan AYAZ BİLİRa, İlayda LOÇLAR KARAALPa, ${ }^{[0}$ Ateş KARATEKEa, \\ a Department of Obstetrics and Gynecology, İstanbul Medeniyet University Göztepe Training and Researching Hospital, İstanbul, TURKEY
}

\begin{abstract}
Neurofibromatosis (NF) is an autosomal dominant genetic syndrome which can be seen in 1: 3000- 1:5000 women. Women with NF without infertility problem may have one or more pregnancies during reproductive years. Pregnancies of patients with neurofibromatosis are known to be complicated by intrauterine growth retardation, preterm birth, gestational hypertension and preeclampsia, but history of abruption is very rare in few cases. Physicians should be aware of the complications of this unique pregnancy and manage it multidisciplinary. The purpose of this case report is to share the experience of the pregnancy with neurofibromatosis, having epilepsy and unexplained embolism history, which is complicated with intrauterine growth retardation and placental abruption
\end{abstract}

Keywords: Neurofibromatosis; intrauterine growth retardation; placental abruption; pregnancy

Neurofibromatosis (NF) is an autosomal dominant syndrome characterized by variable clinical expressions ranging from benign peripheral and central tumors to severe orthopedic complications and functional disorders. ${ }^{1}$ There are two types NF according to presentations. Type 1 (Von Recklinghausen's), abnormality on chromosome $17 \mathrm{q}$, shows multiple tumors of spinal or cranial nerves, skin tumors and intracranial meningioma. On the other hand, type 2, abnormality on chromosome 22 , is characterized as multiple tumors of the nervous system specifically bilateral acoustic neuromas. ${ }^{2}$ The incidence of NF1 in pregnancy is similar as in the general population which is ranging between 1:3000 to $5000 .{ }^{3} \mathrm{NF} 1 \mathrm{pa}-$ tients are thought to have approximately a decade less life expectancy with normal fertility. ${ }^{4}$ Women with $\mathrm{NF}$ without infertility problem may have one or more pregnancies during reproductive years. As a physician, we should have the knowledge to manage these pregnancies and consult them properly. Several studies show relation between hypertension, preeclampsia, intrauterine growth retardation (IUGR), preterm labor, cesarean delivery and NF1 patients. ${ }^{4}$ In this paper, we report our experience in the case of nulliparous patient with neurofibromatosis complicated with generalized tonic-clonic epileptic seizures during pregnancy resulting with symmetric intrauterine growth retardation and preterm caesarian section due to placental abruption.

\section{CASE REPORT}

A 33-year-old nulliparous woman was admitted to our facility due to symmetric intrauterine growth retardation (IUGR) at 33 weeks and 2 days. She was diagnosed with neurofibromatosis with the neurofibromas pathology of skin tumor biopsy and café-aulait macules 9 years ago complicated with generalized tonic-clonic epileptic seizures (GTCS) 1 per 2-3 years. She was using levatiracetam $500 \mathrm{mg} 2$ times a day before pregnancy. At $3^{\text {rd }}$ month of pregnancy, it is learned that the patient has decreased her antiepileptic drug dosage without supervision and a neurologist evaluated the patient after recurrence of GTCS and decided to continue the same dosage of levatiracetam used prepregnancy. After that, the epileptic attack did not occur again during the pregnancy. On the other hand, she had a history of pulmonary embolism 3 years ago and started Aspirin $100 \mathrm{mg}$ daily. At $20^{\text {th }}$ gestational week, the fetus was in the normal range during the second trimester anatomic screening ex-

Correspondence: İlayda LOÇLAR KARAALP

Department of Obstetrics and Gynecology, İstanbul Medeniyet University Göztepe Training and Researching Hospital, İstanbul, TURKEY E-mail: iloclar@ku.edu.tr

Peer review under responsibility of Journal of Clinical Obstetrics \& Gynecology. 
cept bilateral uterine notch. Symmetric IUGR were detected at 33 gestational weeks. She hasn't have any medical problems related to the pregnancy. On her admission, her vital signs were normal and unfractionated heparin was started as a prophylactic dose according to her weight. The patient was planned to undergo cesarean section after completion of corticosteroid therapy because of severe IUGR $(<3 p)$ and absent umbilical artery end diastolic flow. However, during her follow-up, acute fetal distress was recorded at non-stress test (NST) and sudden vaginal bleeding occurred and she had emergent caesarian section due to placental abruption and a male baby was born without complication with Apgar scores of $1^{\text {st }}$ and $5^{\text {th }}$ minutes were 2 and 6 , respectively. Informed consent form was obtained from the patient for this case report.

\section{DISCUSSION}

Neurofibromatosis is a relatively common autosomal dominant genetic disease caused by NFI gene mutation that presents with variable phenotypic expressivity such as cutaneous (cafe-au-lait macules, inguinal and axillary freckles) and neural (neurofibromas, plexiform neurofibromas, Lisch spots, optic nerve gliomas) signs. NF1 incidence is between 1:3000 to 5000 in pregnancy. ${ }^{3}$ Neurofibromatosis 1 diagnosis is usually based on clinical features and generally, genetic testing is not warranted. According to the 1988 National Institutes of Health Consensus Development Conference, NF1 is diagnosed by presenting 2 of the following clinical features: (1) 6 or more café-au-lait spots, (2) axillary or groin freckling, (3) 2 or more Lisch nodules, (4) 2 or more neurofibromas, (5) optic pathway gliomas (OPGs), (6) bone dysplasia, and (7) a first-degree family relative with NF1. ${ }^{5}$ Our patient was diagnosed with NF1 with more than 2 neurofibromas and more than 6 café-aulait macules 9 years ago by meeting diagnostic criteria for NF1 developed by the National Institutes of Health.

Contrary to previous studies, current studies have shown that maternal and fetal outcomes are better in pregnant women with NF. Past studies reported the rate of live birth around 50-75\%. ${ }^{2,6}$ However, recent retrospective studies reported rate of live birth is nearly $100 \%$ although preterm birth rate and low birthweight are high in NF patients. ${ }^{4,7,8}$ This improvement can be attributed to the development of the success of preterm care in neonatal intensive care units. Even, in 2017 Leppävirta et al. reported the pregnancy period of NF patient is shorter than control group. ${ }^{7}$

In our patient, IUGR started around 28 weeks. In the literature, Segal et al. reported NF patient have IUGR in 13 pregnancies. ${ }^{1}$ Terry et al. supported the significant relation between IUGR and NF pregnancies in 1553 patients in $2013 .{ }^{4}$ Pregnant women with neurofibromatosis are usually complicated with preterm labor and IUGR. It is known that preterm labor and IUGR are associated with placental pathology, but so far no studies on the relationship between neurofibromatosis and placenta have been performed. The relationship between neurofibromatosis and placental pathologies would be searched in further studies.

In 1991, Sharma reported the incidence of gestational hypertension and preeclampsia is $70 \%$ among $10 \mathrm{NF}$ patients and she also concluded that past history of preeclampsia and poor perinatal outcome are bad prognostic factors for following pregnancies. ${ }^{8}$ Many studies support the relation between preeclampsia, hypertension and NF. ${ }^{4,7}$ Dugoff showed common obstetrical complications such as eclampsia, preterm delivery, gestational hypertension are not more frequent in women with NF-1 than in the general population in 180 pregnancies. $^{2}$ Eclampsia and intracranial hemorrhage during pregnancy of NF patients is reported in one case report by Agarwal in 2002. ${ }^{9}$ In addition, HELLP syndrome and NF was also seen in 2 patients in the literature. ${ }^{9,10}$ There was not any hypertensive complication in our patient. Physicians should be aware of these complications to intervene quickly in these cases.

Patients with neurofibromatosis who have an underlying tumor may present pulmonary embolism. In 2013, a case report shows that a male NF-1 patient with periampullary duodenal carcinoma has experienced recurrent fatal embolism attack. ${ }^{11}$ However, in the literature there is no patient with spontaneous unexplained embolism attack with neurofibromatosis. Our patient has spontaneous unexplained embolism 
attack 3 years ago and she started to use Aspirin 100 $\mathrm{mg}$. To our knowledge, this patient is the unique case in the literature experiencing unexplained embolism with neurofibromatosis.

Epilepsy attacks due to nervous system involvement are seen in patients with neurofibromatosis. Antiepileptic drugs are used to prevent these epileptic attacks. Prenatal exposure to the antiepileptic drugs are associated with congenital malformations and neurodevelopment disorders in offspring, however lamotrigine, levetiracetam and oxcarbazepine are more favorable outcomes among the antiepileptic drugs. ${ }^{12}$ Our patient had epilepic attacks before pregnancy and was started levatiracetam. However, at $3^{\text {rd }}$ month of the pregnancy she has epileptic attack due to treatment incompatibility, continuing back to the same dosage of levatiracetam ceased attacks and no recurrence occurred through pregnancy.

Our patient had sudden painful vaginal bleeding during follow-up. Placental abruption was diagnosed via ultrasonography and confirmed during the cesarean section. There are few cases in the literature with abruption of placenta during pregnancy in pregnant women with NF. ${ }^{2,7}$ Eventhough placental abruption is mostly associated with hypertensive disease of pregnancy, during epileptic seizure, ablation placenta may develop as a result of abdominal trauma due to the sudden stretching or contraction of the underlying uterine wall. ${ }^{13}$ In our patient, there was no history of abdominal trauma or hypertensive disease to explain the placental abruption. Further studies are needed to clarify the association between the placental abruption and pregnant NF patients.

The rate of cesarean section of the NF patients is more common than normal population. ${ }^{1,4}$ In the literature, cesarean delivery rate is around $\% 30-\% 36^{2,14}$ Mostly higher rate of failed induction is the cause of the increase in cesarean deliveries. In our patient acute placental abruption was the cause of the cesarean delivery.
It is known that pregnancy of neurofibromatosis patients could be complicated for both mother and baby. The pregnancy period is shorter among NF patients. ${ }^{7}$ Close follow up and managing pregnancy with multidisciplinary approach would increase the rate of live birth and provide better outcomes. Since NF is inherited as autosomal dominant, it is necessary to inform the couples planning pregnancy about the possibility of genetic transition from parents to offspring and parents who carry mutation of NF genes can be suggested preimplantation genetic diagnosis to prevent recurrence of this disorder. If the parents don't prefer to perform pre-implantation genetic diagnosis, genetic counselling can prepare the parents for the effect of emotional distress and facilitated understanding of their baby's condition and prognosis. In conclusion, we report a patient with neurofibromatosis complicated with seizure during pregnancy and had symmetric intrauterine growth retardation and preterm caesarian section due to placental abruption and discuss with literature review.

\section{Source of Finance}

During this study, no financial or spiritual support was received neither from any pharmaceutical company that has a direct connection with the research subject, nor from a company that provides or produces medical instruments and materials which may negatively affect the evaluation process of this study.

\section{Conflict of Interest}

No conflicts of interest between the authors and / or family members of the scientific and medical committee members or members of the potential conflicts of interest, counseling, expertise, working conditions, share holding and similar situations in any firm.

\section{Authorship Contributions}

Idea/Concept: Reyhan Ayaz Bilir, Illayda Loçlar Karaalp; Design: Reyhan Ayaz Bilir, İlayda Loçlar Karaalp; Control/Supervision: Ateş Karateke, Reyhan Ayaz Bilir; Data Collection and/or Processing: Ilayda Loçlar Karaalp; Analysis and/or Interpretation: Reyhan Ayaz Bilir; Literature Review: Illayda Loçlar Karaalp; Writing the Article: Ilayda Loçlar Karaalp, Reyhan Ayaz Bilir; Critical Review: Reyhan Ayaz Bilir, Ateş Karateke. 


\section{REFERENCES}

1. Segal D, Holcberg G, Sapir O, Sheiner E, Mazor M, Katz M. Neurofibromatosis in pregnancy. Maternal and perinatal outcome. Eur J Obstet Gynecol Reprod Biol. 1999;84(1):5961.[Crossref] [PubMed]

2. Dugoff L, Sujansky E. Neurofibromatosis type 1 and pregnancy. Am J Med Genet. 1996;66(1):7-10.[Crossref] [PubMed]

3. Chetty SP, Shaffer BL, Norton ME. Management of pregnancy in women with genetic disorders: Part 2: Inborn errors of metabolism, cystic fibrosis, neurofibromatosis type 1 , and Turner syndrome in pregnancy. Obstet Gynecol Surv. 2011;66(12):765-7.[Crossref] [PubMed]

4. Terry AR, Barker FG 2nd, Leffert L, Bateman BT, Souter I, Plotkin SR. Neurofibromatosis type 1 and pregnancy complications: a population-based study. Am J Obstet Gynecol. 2013;209(1):46.e1-8.[Crossref] [PubMed]

5. Friedman JM. Neurofibromatosis 1. 1998 Oct 2 [Updated 2019 Jun 6]. In: Adam MP, Ardinger HH, Pagon RA, et al., editors. 8.[Crossref] [PubMed]
GeneReviews $₫$ [Internet]. Seattle (WA): University of Washington, Seattle; 1993-2020. Available from: [Link]

6. Hadi HA. Clinical significance of neurofibromatosis in pregnancy. Am J Perinatol. 1995;12(6):459-61.[Crossref] [PubMed]

7. Leppävirta J, Kallionpää RA, Uusitalo E, Vahlberg T, Pöyhönen M, Timonen S, et al. The pregnancy in neurofibromatosis 1: a retrospective register-based total population study. Am J Med Genet A. 2017;173(10):2641.

8. Sharma JB, Gulati N, Malik S. Maternal and perinatal complications in neurofibromatosis during pregnancy. Int J Gynaecol Obstet. 1991;34(3):221-7. [Crossref] [PubMed]

9. Agarwal U, Dahiya P, Sangwan K. Recent onset neurofibromatosis complicating eclampsia with maternal death: a case report. Arch Gynecol Obstet. 2003;268(3):241-242.[Crossref] [PubMed]

10. Hagymásy L, Tóth M, Szücs N, Rigó J Jr. Neu- rofibromatosis type 1 with pregnancy-associated renovascular hypertension and the syndrome of hemolysis, elevated liver enzymes, and low platelets. Am J Obstet Gynecol. 1998;179(1):272-4.[Crossref] [PubMed]

11. Njei B, Sanchez H. Neurofibromatosis type 1 , recurrent pulmonary embolism, and a periampullary carcinoid tumor: is there a link? Conn Med. 2013;77(2):77-80.[PubMed]

12. Tomson T, Battino D, Perucca E. Teratogenicity of antiepileptic drugs. Curr Opin Neurol. 2019;32(2):246-52.[Crossref] [PubMed]

13. Melamed N, Aviram A, Silver M, Peled Y, Wiznitzer A, Glezerman $M$, et al. Pregnancy course and outcome following blunt trauma. J Matern Fetal Neonatal Med. 2012;25(9):16127.[Crossref] [PubMed]

14. Cesaretti C, Melloni G, Quagliarini D, Fogliani R, Zaina B, Bedeschi MF, et al. Neurofibromatosis type 1 and pregnancy: maternal complications and attitudes about prenatal diagnosis. Am J Med Genet A. 2013;161A(2): 386-8.[Crossref] [PubMed] 